\section{Serono to pilot Nebula's blockchain for genomes}

Nebula Genomics announced in June its first partnership with pharma to use its blockchain-based platform. EMD Serono will use Nebula's network of anonymized genomic data in a lung cancer project. Founded in 2016 by George Church and two Harvard students, Kamal Obbad and Dennis Grishin, Nebula is one of a small cadre of companies that have set up blockchain-based platforms to enable people to maintain control of their genome and manage access to it in a secure, yet transparent, environment. For Serono, a subsidiary of Merck KGaA of Darmstadt, Germany, the collaboration has the potential to provide scientific insights that will help researchers understand the causes of disease and accelerate discovery and drug development. In exchange for access to their data, lung cancer patients will be offered a free, high-coverage wholegenome sequencing, which could help them make better treatment choices. According to Nebula's founders, two issues primarily keep people from getting their genome sequenced: cost and privacy concerns. As a result, relatively few human genomes have been sequenced so far, slowing the development of genome-based therapies. This new effort aims to solve these problems, leading to greater numbers of genomes becoming available to drug developers. By far the largest collections of genomic information are in the hands of directto-consumer genomics companies, like 23andMe and Ancestry.com, which are estimated to have over 26 million customers. However, the data they provide are limited to 600,000 singlenucleotide polymorphisms (SNPs) or only $0.02 \%$ of the human genome. Since 2018, Nebula has been offering a low-pass sequence for only $\$ 99$, which can reveal information on ancestry and some non-medical traits. Through partnerships like the one with EMD Serono, certain customers will now get their complete genomes for free.

Published online: 2 July 2019 https://doi.org/10.1038/s41587-019-0187-y gun," says Topol. "They don't have the data, and they have no right to charge people."

But the data supporting scientific wellness come not, Hood argues, from the traditional, double-blinded randomized controlled trial that his critics call for. Randomized controlled trials wipe out, rather than enhance, the individual variation that is the key to predicting disease and maintaining health. What's needed are " $n$-ofone" studies, in which each individual acts as his or her own control. "Evidence-based medicine as we know it is a disaster," says Hood, who predicts that it will eventually be replaced by $n$-of-one studies that he terms "dense phenotyping."

Notwithstanding the massive challenge of focusing on wellness and prevention, rather than disease, investors have not lost faith. "There's a huge future in consumer wellness," tweeted Arch's Nelsen; it's just about getting the right combination of price, product and distribution channel. For Hood, Arivale was not a failure. It was an "unmitigated success," as it demonstrated the power of dense phenotyping to generate actionable possibilities to improve health and prevent disease and, finally, in underscoring the importance of psychology in supporting individuals to change their behavior. The coaching was what distinguished Arivale from rivals like 23 andMe, a genetic testing company; Orig3n; Mayo Clinic's GeneGuide; and Helix.

A similarly comprehensive offering to Arivale's is from Q Bio, cofounded in 2015 by Michael Snyder, Garry Choy and entrepreneur Jeffrey Kaditz. Q Bio promises consumers a full health snapshot in 75 minutes, but at $\$ 3,500$ a go, it's still expensive. Perhaps learning from Arivale's mistakes, the company is focused on "being a partner for medical practice," says Kaditz. Consumers share their personal ' $Q$ report' directly with primary care physicians, with an emphasis on early detection and prevention of diseases with high mortality. Helix, a spin-out of sequencing giant Illumina, is also paring back its consumer-focused DNA products to focus instead on health systems and payers.

Fully integrated wellness groups like Q Bio also envision selling their products more widely, including to payers. Q Bio's Kaditz thinks the company can make the Q protocol a "prevalent, established tool for primary care" in the "near future, as the cost of [measuring] everything will approach the cost of [measuring] one thing."

Hood, a self-proclaimed optimist, also predicts that the falling cost of testing means that in five years "we'll persuade payers to fund" the battery of tests Arivale was offering. Meantime, he's going to bring the "best of Arivale" to family practitioners within Providence St Joseph Health, the not-for-profit health system of which he is CSO. Other payers have also begun to use genomic tools more systematically in disease prevention: Geisinger Health in 2018 added DNA (exome) sequencing to its routine screening program.

Scientific wellness is coming, but not as fast as Arivale's investors hoped. The company was perhaps too bold in offering so much novelty in one go: new science, a new kind of evidence generation, a new delivery channel, and a new way to think about health and disease. Its challenge was not only diagnosis, but also behavior change. Indeed, working out how to motivate a broad population to engage in a healthy lifestyle over the long term is the really hard question, says Geoffrey Smith, founder and managing partner at health technology firm Digitalis. Do people have to be motivated at the individual level, or could they be grouped? What pricing model would lead to the greatest engagement? In short, "despite being a technology and datadriven investor, I suspect that getting to better [scientific wellness] solutions will have more to do with behavioral economics than merely better sensor technologies," he predicts.

Given those remaining challenges, it is perhaps not surprising that this early variation did not work out. Arivale 1.0 did not get the right combination of price point, product and distribution model. "But we're not giving up," comments Arch Ventures' Nelsen.

Nor is Hood. He's designing a high-school biology module on scientific wellness, and is introducing the concept to medical school students at Washington State University. "One of the most valuable things Arivale gave us was the sense that we can control our own health, make decisions that can impact our lives, how we feel, and our wellness. There is enormously more to come," he says.

Melanie Senior

London, UK

Published online: 12 June 2019

https://doi.org/10.1038/d41587-019-00016-5 